\title{
The effects of professional continuous glucose monitoring as an adjuvant educational tool for improving glycemic control in patients with type 2 diabetes
}

Dulce Adelaida Rivera-Ávila', Alejandro Iván Esquivel-Lu², Carlos Rafael Salazar-Lozano ${ }^{3}, K_{y l a}$ Jones $^{4}$ and Svetlana V. Doubova ${ }^{5^{*}}$

\begin{abstract}
Background: The study objective was to evaluate the effects of professional continuous glucose monitoring (CGM) as an adjuvant educational tool for improving glycemic control in patients with type 2 diabetes (T2D).

Methods: We conducted a three-month quasi-experimental study with an intervention (IGr) and control group (CGr) and ex-ante and ex-post evaluations in one family medicine clinic in Mexico City. Participants were T2D patients with $\mathrm{HbAlc}>8 \%$ attending a comprehensive diabetes care program. In addition to the program, the IGr wore a professional CGM sensor (iPro ${ }^{\mathrm{TM}} 2$ ) during the first 7 days of the study. Following this period, IGr participants had a medical consultation for the CGM results and treatment adjustments. Additionally, they received an educational session and personalized diet plan from a dietitian. After 3 months, the IGr again wore the CGM sensor for 1 week. The primary outcome variable was HbA1c level measured at baseline and 3 months after the CGM intervention. We analyzed the effect of the intervention on $\mathrm{HbA1c}$ levels by estimating the differences-indifferences treatment effect (Diff-in-Diff). Additionally, baseline and three-month CGM and dietary information were recorded for the IGr and analyzed using the Student's paired t-test and mixed-effects generalized linear models to control for patients' baseline characteristics.

Results: Overall, 302 T2D patients participated in the study (IGr, $n=150$; control, $n=152$ ). At the end of the threemonth follow-up, we observed 0.439 mean HbA1C difference between groups $(p=0.004)$, with an additional decrease in HbA1c levels in the IGr compared with the CGr (Diff-in-Diff HbA1c mean of $-0.481 \%$ points, $p=0.023$ ). Moreover, compared with the baseline, the three-month CGM patterns showed a significant increase in the percentage of time in glucose range $(+7.25 ; p=0.011)$; a reduction in the percentage of time above $180 \mathrm{mg} / \mathrm{dl}$ $(-6.01 ; p=0.045)$, a decrease in glycemic variability $(-3.94, p=0.034)$; and improvements in dietary patterns, shown by a reduction in total caloric intake $(-197.66 \mathrm{Kcal} / \mathrm{day} ; p=0.0001)$.

\footnotetext{
* Correspondence: svetlana.doubova@gmail.com

${ }^{5}$ Epidemiology and Health Services Research Unit, CMN Siglo XXI, Mexican

Institute of Social Security, Av. Cuauhtemoc 330, Col. Doctores, Del.

Cuauhtemoc, 06720 Mexico City, Mexico

Full list of author information is available at the end of the article
}

(c) The Author(s). 2021 Open Access This article is licensed under a Creative Commons Attribution 4.0 International License, which permits use, sharing, adaptation, distribution and reproduction in any medium or format, as long as you give appropriate credit to the original author(s) and the source, provide a link to the Creative Commons licence, and indicate if changes were made. The images or other third party material in this article are included in the article's Creative Commons licence, unless indicated otherwise in a credit line to the material. If material is not included in the article's Creative Commons licence and your intended use is not permitted by statutory regulation or exceeds the permitted use, you will need to obtain permission directly from the copyright holder. To view a copy of this licence, visit http://creativecommons.org/licenses/by/4.0/ The Creative Commons Public Domain Dedication waiver (http://creativecommons.org/publicdomain/zero/1.0/) applies to the data made available in this article, unless otherwise stated in a credit line to the data. 
(Continued from previous page)

Conclusion: Professional CGM contributes to reducing HbA1c levels and is an adjuvant educational tool that can improve glycemic control in patients with T2D.

Trial registration: ClinicalTrials.gov: NCT04667728. Registered 16/12/2020

Keywords: Type 2 diabetes, Professional continuous glucose monitoring, Educational tool, Glycemic control

\section{Background}

Diabetes is a global health threat due to the high morbidity, disability-adjusted life years, premature mortality, and healthcare costs attributed to the disease. Currently, nearly half a billion people have diabetes; $90 \%$ have type 2 diabetes and $75 \%$ live in low- and middle-income countries (LMICs) [1]. In 2019, the adult population of North America and the Caribbean had the highest prevalence of diabetes globally (13.3\%) and accounted for $43 \%$ of the world's diabetes-related health expenditures [1].

Although glycemic control is the primary mechanism for preventing acute and chronic complications, disability, and premature mortality among diabetes patients [2, 3], it is achieved by only $20.9-24.9 \%$ of diabetes patients living in LMICs [4]. Laboratory testing for Hemoglobin A1c (HbA1c)-a biochemical marker of the average glycemia level over the previous 2-3 months period-is the gold standard for glucose monitoring [5]. However, HbA1c may not be an appropriate marker for patients with abnormal hemoglobin, end-stage renal disease, or chronic liver disease. Moreover, $\mathrm{HbA} 1 \mathrm{c}$ is not an indicator for daily glucose variability, including hypoglycemic events. To assess daily blood glucose variability, determine individual glycemic targets, and provide personalized treatment of diabetes, patients must perform selfmonitoring of blood glucose (SMBG). However, SMBG fails to provide a complete picture of blood glucose trends and detect hyperglycemic events [6].

Continuous glucose monitoring (CGM) with wearable devices for patients with diabetes has emerged as a method for personalizing treatment plans, aiming at improving glycemic control [7]. CGM devices utilize sensor technology inserted subcutaneously to measure interstitial glucose levels throughout the day. These devices generate glucose profile reports guiding pharmacological and non-pharmacological treatment [7]. Compared with traditional SMBG, patients with diabetes utilizing CGM achieve more significant reductions in glycated hemoglobin, body weight, and caloric intake, and higher adherence to diet and physical activity plans [8-10]. The daily glucose reports generated by CGM can help educate patients on the relationship between self-care, adherence to medication, diet, physical activity, and glycemic control $[7,11]$. In addition, CGM may reduce healthcare costs through improved glucose control and decreased hospital admissions [12, 13].

There are three types of CGM tools on the market: (1) professional CGM; (2) real-time monitoring (stand-alone or connected to a pump) (RT-CGM); and (3) intermittently viewed/flash glucose monitoring (FGM). The professional CGM is a healthcare provider-managed device that generates retrospective glucose profile reports, whereas RT-CGM and FGM are managed by patients and collect real-time glucose readings [14, 15]. These sensors have demonstrated their effectiveness and there is growing evidence on their advantages, disadvantages, and indications for use $[14,15]$.

Mexico is a middle-income country with a high prevalence of diabetes (12\%) and acute and chronic complications due to poor glycemic control $[1,16]$. The Institute of Social Security and Services for State Workers (Instituto de Seguridad y Servicios Sociales de los Trabajadores del Estado-ISSSTE) provides healthcare to active and retired federal government workers and their families. In 2019, ISSSTE covered 11\% (13.5 million) of Mexico's population [17]. Currently, 1 million ISSSTE affiliates have diabetes - the second cause of death for this group [18].

Since 2007, ISSSTE has run the Comprehensive Diabetes Care program (MIDE by its Spanish acronym) to provide care to patients with HbA1c $>7 \%$ through individual consultations and self-care support groups led by multidisciplinary teams made up of family doctors, nutritionists, exercise instructors, nurses, social workers, and psychologists. Between 2007 and 2014, MIDE cared for 97,452 diabetes patients [19]. During this period, the proportion of patients with $\mathrm{HbA} 1 \mathrm{c}>7 \%$ dropped by $25 \%$, the number of hospitalizations over a 12 monthperiod declined by 41 , and $60 \%$ of patients reached metabolic control [19].

Although the results of MIDE are encouraging, there is still room for improvement. The present study's objective was to evaluate the effects of professional CGM as an adjuvant educational tool for improving glycemic control in patients with type 2 diabetes.

We hypothesized that 6-7 days of professional CGM used as an adjuvant educational tool would help to decrease HbA1c levels in patients with type 2 diabetes who use this device compared with those who do not. In addition, professional CGM would help to improve 
patients' dietary patterns (decrease carbohydrates, fat, protein, and total caloric intake) and CGM glucose profile (e.g., decrease time in hyperglycemic range and increase time in glucose range of $70-180 \mathrm{mg} / \mathrm{dl}$ ).

\section{Methods}

From May to October 2017, we conducted a threemonth quasi-experimental study with intervention and control groups and ex-ante and ex-post evaluations in one ISSSTE family medicine clinic in Mexico City. Patients with type 2 diabetes in the MIDE program who were older than 20 years of age, had $\mathrm{HbA1c}>8 \%$ and without diagnosis of a memory disorder were considered eligible participants for the study; those who agreed to participate, were required to sign an informed consent. From May 3 to June 15, 2017, we invited all consecutive type 2 diabetes patients who attended the MIDE program to join the intervention group; we followed the same protocol from June 16 to July 31 to assemble the control group.

The control group followed the MIDE care plan, consisting of at least two consultations with a medical doctor and HbA1c measurements at baseline and 3 months later, as well as weekly self-care educational group activities. The baseline consultation included a review of HbA1c levels and treatment adjustments.

At the beginning of the study, the intervention group had a professional CGM device (iPro ${ }^{\mathrm{m}} 2$, Medtronic, USA) inserted subcutaneously for 7 days. Before the CGM insertion, the intervention group received a training session on how to use and calibrate the device through three daily glucometer readings of capillary glucose. Moreover, intervention group patients were trained to record daily information on their medications, including the times and dosages taken; their diet, including the foods and portions consumed; and their physical activity practices. After 6 days of device use, participants had a consultation with a family physician trained in diabetes to interpret the CGM report results and adjust their treatment. In addition, a dietitian provided an educational session and personalized diet plan guided by the CGM results. Participants in the intervention group were also advised to attend regular MIDE program activities. After 3 months, the intervention group wore the sensor again for 1 week and their HbA1C levels were measured.

After the 3-month study period, the intervention and control groups continued their participation in the MIDE program.

The primary outcome variable was HbA1c level, measured at baseline and three-month evaluations in both groups. Additionally, baseline and three-month CGM data based on the 2017 international consensus on CGM metrics [20] and dietary information were recorded for the intervention group. The CGM variables included: number of days that the participant wore the CGM; percentage of time the CGM was active; mean glucose levels (mg/dl); glycemic variability measured through standard deviation (SD); time in range, defined as the percentage of time that patients' CGM glucose readings were in the target range $(70-180 \mathrm{mg} / \mathrm{dl})$; percentage of time above $180 \mathrm{mg} / \mathrm{dl}$ and $250 \mathrm{mg} / \mathrm{dl}$; percentage of time below $70 \mathrm{mg} / \mathrm{dl}$ and $54 \mathrm{mg} / \mathrm{dl}$; percentage of the area over the blood concentration-time curve; and percentage of the area under the blood concentrationtime curve. Dietary variables were measured through 24$h$ recall reports, which included measuring daily total caloric intake and caloric intake broken down by carbohydrates, proteins, and fat (Kcal/day).

The study covariates included participants' baseline general and clinical characteristics: sex, age, educational level, nutritional status measured by body mass index (BMI: $\mathrm{kg} / \mathrm{m} 2$ ), time since diagnosis, and pharmacological treatment (insulin, metformin, glibenclamide, pioglitazone, and linagliptin). We also recorded doctors' modifications to treatment following the baseline HbA1c (in both groups) and CGM (in the intervention group) data.

The sample size for the primary outcome (HbA1c) was estimated using the formula to test a change in the mean of two normally distributed samples in longitudinal studies [21]. An average decrease of at least 0.7\% of $\mathrm{HbAlc}$ in the intervention group compared with the control group was considered to be clinically relevant. Other assumptions included: $\alpha=0.05$ (for one-sided hypothesis) and a power of $90 \%$. The number of patients by group was 143 , assuming a drop-out rate of $20 \%$.

\section{Statistical analysis}

We performed bivariate and inferential analyses. The bivariate analysis included a comparison of the study variables between both groups. We compared the groups using the Student's t-test for continuous variables and the Chi-square test for categorical variables. The comparison between the baseline and three-month evaluations of the CGM and dietary pattern variables in the intervention group was conducted using the Student's paired t-test.

The intervention's impact on the primary outcome variable (HbA1c) was assessed by estimating the differences-in-differences (Diff-in-Diff) treatment effect using a Diff-in-Diff estimator [22]. As the study lacked randomization, we adjusted the results of the Diff-inDiff treatment effects by the participants' baseline covariates. To control for possible missing data bias due to participant drop-out during the follow-up, we performed the study results' sensitivity analyses using intent-totreat analyses [23]. We conducted a Diff-in-Diff analysis for the primary outcome variable, carrying forward the 
baseline observation for those participants without a three-month evaluation. We did not apply the inverse probability weighting (IP-weighting) technique [24, 25] as an alternative to treat missing data given that the Diff-in-Diff analysis in STATA does not allow the use of weights.

We performed the mixed-effects generalized linear model to evaluate changes in each of the CGM and dietary variables in the intervention group and accounted for the correlation between repeated measurements (baseline and three-month). In the analysis, we controlled for patients' baseline characteristics, such as sex, age, time since diagnosis, BMI, baseline treatment, and treatment modifications. We applied the IP-weighting technique $[24,25]$ to the multilevel mixed-effects generalized linear models to avoid missing data bias. This technique is based on assigning a weight to each individual with complete information, so that they account both for themselves and others with similar characteristics who have missing information; it creates a pseudopopulation that eliminates missing data and where the effect of the exposure is the same as in the original population. The denominator for stabilized inverse probability weights was the probability of "having missing data" given baseline covariates, such as sex, age, BMI, time since diagnosis, and type of baseline treatment. The numerator was the probability of "having missing data" regardless of the covariates.

$P$-values $<0.05$ were interpreted as statistically significant. The analyses were performed using the software Stata 14.0 (Stata Corp, College Station, TX, USA).

\section{Patient and public involvement}

Patients or the public were not involved in the design, or conduct, or reporting, or dissemination of the present study.

\section{Ethics approval}

The ISSSTE Ethics Committee approved the study (registry number 318.17 ).

\section{Results}

Overall, 302 (87\%) out of 342 invited patients agreed to participate in the study. We allocated 150 patients to the intervention and 152 to the control group. The main cited reason for not participating was a lack of time to complete the study activities.

The control (CGr) and intervention groups (IGr) had similar baseline general and clinical characteristics. Most participants were women (CGr 65.3\%; IGr 71.7\%); their average age ranged between 59 (IGr) and 60 years (CGr); and most had completed high school or a university degree (CGr 62\%; IGr 59.2\%). Both groups had a high prevalence of overweight/obesity (CGr 86\%; IGr 81.6\%). The average time since diagnosis was 14 years (Table 1).

The control and intervention groups had statistically significant differences in their diabetes treatment and baseline levels of HbA1c. Compared to the control group, more IG participants had received insulin (CGr 48.7\%, IGr 72.4\%) and fewer had received glibenclamide (CGr 35.3\%, IGr 21.1\%). Additionally, the average baseline $\mathrm{HbA1c}$ level was higher in the intervention group (CGr 9.3\%; IGr 9.8\%). Following the baseline evaluation, a higher percentage of CGr participants had modifications made to their pharmacological treatment $(\mathrm{CGr}$ 66.0\%; IGr 48.7\%).

Both groups lost participants in the follow-up period; $8 \%$ of control group and $14.5 \%$ of intervention group participants did not complete the three-month evaluation. In the control group, the primary reasons for leaving the study were a lack of time or money to cover transportation costs to consultations; similarly, in the intervention group, the inability to pay for travel to the clinic for the CGM sensor insertion was cited as the main reason for discontinuing in the study. Additionally, four patients that declined the sensor's insertion accepted the three-month HbA1C measurement. Furthermore, 14 patients who wore the sensor for the threemonth evaluation had missing data in their CGM records (Table 1).

Table 2 shows the effect of the intervention on the HbA1c levels when we compared both groups. The mean $\mathrm{HbA1C}$ difference between the intervention and control group was $0.415 \%$ points $(p=0.010)$ for those who completed three-month evaluation and it was $0.439 \%$ points ( $p=0.004$ ) when the baseline observations were carried forward for 34 participants without threemonth evaluations. The adjusted Diff-in-Diff estimator between intervention and control groups showed an additional decrease of HbA1c levels by $0.609(p=0.006)$ for patients in the intervention group who completed a three-month evaluation and an additional reduction by $0.481 \%$ points $(p=0.023)$ in the intervention group when the baseline observations were carried forward for those without three-month evaluations.

Table 3 presents the results of the baseline and the three-month evaluation, and the changes in the continuous glucose monitoring and dietary patterns in the intervention group. At baseline, patients wore the CGM sensor for an average of 6.4 days, and it was active for $68.2 \%$ of the time. The mean glucose levels were 202.2 $\mathrm{mg} / \mathrm{dl}$ (SD: 50.7), with low glycemic variability measured through SD 57.3 (SD: 19.0), as SD was less than the mean glucose divided by 3 [26].

The CGM glucose readings reported a time in range of $43.4 \%$ (the percentage of time that patients were in the target glucose range) (SD: 25.9), 54.9\% (SD: 27.0) 
Table 1 Participants' characteristics

\begin{tabular}{|c|c|c|}
\hline Characteristics & $\begin{array}{l}\text { Control group } \\
n=150 \\
\mathrm{n}(\%)\end{array}$ & $\begin{array}{l}\text { Intervention group } \\
n=152 \\
\mathrm{n}(\%)\end{array}$ \\
\hline \multicolumn{3}{|l|}{ General characteristics } \\
\hline Sex, female & $98(65.3)$ & $109(71.7)$ \\
\hline Age, mean (SD) & $60.0(9.2)$ & $59.0(9.5)$ \\
\hline \multicolumn{3}{|l|}{ Educational level } \\
\hline Elementary school or less & $21(14.0)$ & $19(12.5)$ \\
\hline Secondary school & $36(24.0)$ & $43(28.3)$ \\
\hline High school & $62(41.3)$ & $60(39.5)$ \\
\hline University degree & $31(20.7)$ & $30(19.7)$ \\
\hline \multicolumn{3}{|l|}{ Clinical characteristics } \\
\hline Body mass index $\left(\mathrm{kg} / \mathrm{m}^{2}\right)$, mean (SD) & $30.3(5.7)$ & $29.4(4.7)$ \\
\hline \multicolumn{3}{|l|}{ Nutritional status } \\
\hline Normal weight (BMl: $18.5-24.9$ kg/m²) & $21(14.0)$ & $28(18.4)$ \\
\hline Overweight (BMI: 25.0-29.9kg/m²) & $63(42.0)$ & $61(40.1)$ \\
\hline Obesity $\left(\mathrm{BMI} \geq 30 \mathrm{~kg} / \mathrm{m}^{2}\right)$ & $66(44.0)$ & $63(41.5)$ \\
\hline Time since diabetes diagnosis (years), mean (SD) & $14.3(9.3)$ & $14.0(8.1)$ \\
\hline \multicolumn{3}{|l|}{ Baseline pharmacologic treatment } \\
\hline Insulin**** & $73(48.7)$ & $110(72.4)$ \\
\hline Metformin & $115(76.7)$ & $123(80.9)$ \\
\hline Glibenclamide** & $53(35.3)$ & $32(21.1)$ \\
\hline Pioglitazone & $6(4.0)$ & $10(6.6)$ \\
\hline Linagliptin & $46(30.7)$ & $56(36.8)$ \\
\hline Baseline $\mathrm{HbA} 1 \mathrm{c}(\%)$, mean (SD)*** & $9.3(1.0)$ & $9.8(1.4)$ \\
\hline Modifications to treatment following the baseline evaluation* & $99(66.0)$ & $74(48.7)$ \\
\hline Loss of follow-up & $12(8.0)$ & $22(14.5)$ \\
\hline Missing CGM information at three-month evaluation & & $14(9.2 \%)$ \\
\hline
\end{tabular}

SD Standard deviation

${ }^{*} p<0.05 ;{ }^{* *} p<0.01 ;{ }^{* * *} p<0.001 ;{ }^{* * * *} p<0.0001$

above $180 \mathrm{mg} / \mathrm{dl}$, and $1.4 \%$ (SD: 3.5 ) below $70 \mathrm{mg} / \mathrm{dl}$. The percentage of the area over the blood concentration-time curve was 61.3 (SD: 43.1), and the percentage of the area under the blood concentrationtime curve was 0.22 (SD: 0.78).

Regarding caloric consumption, patients in the intervention group consumed $1334.6 \mathrm{Kcal} /$ day (SD: 443.7); an average of $603.7 \mathrm{Kcal} /$ day (SD: 235.3) were from carbohydrates and an average of $431.9 \mathrm{Kcal} /$ day (SD: 235.1) were from fat.
Compared with the baseline, the three-month CGM patterns showed a significant improvement in patients' metabolic control. We observed a reduction in the mean glucose levels $(-11.64 ; 95 \%$ confidence interval [95\% $\mathrm{CI}]:-22.92,-0.36, p=0.0216)$ and glycemic variability $(-3.93$; $95 \% \mathrm{CI}:-7.57,-0.29)$; there was also a substantial increase in the percentage of time in range (mean increase of $+7.65 ; 95 \%$ CI:1.86, 13.44, $p=0.0050)$ and a reduction in the percentage of time above $180 \mathrm{mg} / \mathrm{dl}$

Table 2 Effect of the intervention on $\mathrm{HbA} 1 \mathrm{C}$ levels

\begin{tabular}{|c|c|c|c|c|c|}
\hline & \multirow{2}{*}{$\begin{array}{l}\text { Baseline }(n=302) \\
\text { Diff }(T-C)\end{array}$} & \multicolumn{2}{|c|}{ Three-month $(n=268)$} & \multicolumn{2}{|c|}{ Three-month with baseline observation carried forward $(n=302)$} \\
\hline & & Diff (T-C) & Diff-in-Diff & Diff (T-C) & Diff-in-Diff \\
\hline & $\beta$ adjusted & $\beta$ adjusted & $\beta$ adjusted & $\beta$ adjusted & $\beta$ adjusted \\
\hline $\mathrm{HbA1C}$ & $1.024^{*}$ & $0.415^{*}$ & $-0.609^{* *}$ & $0.439^{* *}$ & $-0.481^{*}$ \\
\hline
\end{tabular}

T-intervention group; C-control group; Diff (T-C) and Diff-in-Diff estimator controlled for covariates (sex, age, educational level, nutritional status body mass index, time since diagnosis and type of pharmacological treatment) and the baseline treatment modification

${ }^{*} p<0.05$; ${ }^{* *} p<0.01$ 
Table 3 Continuous glucose monitoring and dietary patterns in intervention group

\begin{tabular}{|c|c|c|c|c|c|c|}
\hline & \multicolumn{2}{|c|}{ Baseline evaluation } & \multicolumn{2}{|c|}{ Three-months evaluation } & \multicolumn{2}{|c|}{$\begin{array}{l}\text { Changes between } \\
\text { three-months and } \\
\text { baseline evaluation }\end{array}$} \\
\hline & $\begin{array}{l}\text { mean } \\
(\mathrm{SD})\end{array}$ & $\begin{array}{l}\text { median (minimum, } \\
\text { maximum) }\end{array}$ & $\begin{array}{l}\text { mean } \\
\text { (SD) }\end{array}$ & $\begin{array}{l}\text { median (minimum, } \\
\text { maximum) }\end{array}$ & mean & $\begin{array}{l}95 \% \text { Conf. } \\
\text { Interval }\end{array}$ \\
\hline Continuous glucose monitoring patterns & $n=152$ & & $n=112$ & & $n=112$ & \\
\hline Number of days CGM worn & $6.4(0.61)$ & $6(2,7)$ & $6.4(0.73)$ & $6(4,8)$ & -0.02 & $-0.21,0.17$ \\
\hline Percentage of time CGM was active & $\begin{array}{l}68.2 \\
(18.1)\end{array}$ & $69.3(1.1,93.1)$ & $\begin{array}{l}72.0 \\
(12.2)\end{array}$ & $69.2(40.3,98.9)$ & 3.03 & $-0.74,6.81$ \\
\hline Mean glucose levels, mg/dl & $\begin{array}{l}202.2 \\
(50.7)\end{array}$ & $198(103,397)$ & $\begin{array}{l}190.9 \\
(51.9)\end{array}$ & $181.5(104,362)$ & $-11.64^{*}$ & $-22.92,-0.36$ \\
\hline $\begin{array}{l}\text { Glycemic variability measured through standard } \\
\text { deviation }\end{array}$ & $\begin{array}{l}57.3 \\
(19.0)\end{array}$ & $56(11,115)$ & $\begin{array}{l}53.3 \\
(17.8)\end{array}$ & $52.5(13,111)$ & $-3.93^{*}$ & $-7.57,-0.29$ \\
\hline Percentage of time in range $(70-180 \mathrm{mg} / \mathrm{dl})$ & $\begin{array}{l}43.4 \\
(25.9)\end{array}$ & $40(0,93)$ & $\begin{array}{l}50.9 \\
(28.7)\end{array}$ & $52.5(0,100)$ & $7.65^{*}$ & $1.86,13.44$ \\
\hline Percentage of time above range (> $180 \mathrm{mg} / \mathrm{dl}$ ) & $\begin{array}{l}54.9 \\
(27.0)\end{array}$ & $58(1,100)$ & $\begin{array}{l}48.3 \\
(29.4)\end{array}$ & $46(0,100)$ & $-6.57^{*}$ & $-12.73,-0.41$ \\
\hline Percentage of time above range (> $250 \mathrm{mg} \mathrm{dl}$ ) & $\begin{array}{l}23.9 \\
(23.2)\end{array}$ & $17.5(0,100)$ & $\begin{array}{l}20.3 \\
(23.3)\end{array}$ & $11.5(0,96)$ & -3.0 & $-8.0,1.9$ \\
\hline Percentage of time below range $(<70 \mathrm{mg} / \mathrm{dl})$ & $1.4(3.5)$ & $0(0,21)$ & $0.9(2.2)$ & $0(0,14)$ & -0.49 & $-1.26,0.27$ \\
\hline Percentage of time below range $(<54 \mathrm{mg} / \mathrm{dl})$ & $0.9(4.9)$ & $0(0,51)$ & $0.2(0.8)$ & $0(0,5)$ & -0.86 & $-1.91,0.19$ \\
\hline $\begin{array}{l}\text { Percentage of the area over the blood } \\
\text { concentration-time curve }\end{array}$ & $\begin{array}{l}61.3 \\
(43.1)\end{array}$ & $52(0.3,246.9)$ & $\begin{array}{l}52.7 \\
(43.6)\end{array}$ & $43(0,212.3)$ & -8.50 & $-17.93,0.93$ \\
\hline $\begin{array}{l}\text { Percentage of the area under the blood } \\
\text { concentration-time curve }\end{array}$ & $\begin{array}{l}0.22 \\
(0.78)\end{array}$ & $0(0,6.4)$ & $\begin{array}{l}0.09 \\
(0.29)\end{array}$ & $0(0,1.6)$ & -0.13 & $-0.29,0.04$ \\
\hline \multicolumn{7}{|l|}{ Dietary patterns } \\
\hline Daily caloric intake, Kcal/day & $n=152$ & & $n=122$ & & $n=122$ & \\
\hline Total & $\begin{array}{l}1334.6 \\
(443.7)\end{array}$ & $1250(538,3157)$ & $\begin{array}{l}1144.8 \\
(295.6)\end{array}$ & $1108.5(456,2085)$ & $-189.83^{*}$ & $-270.6,-109.0$ \\
\hline From carbohydrates & $\begin{array}{l}603.7 \\
(235.3)\end{array}$ & $576(68,1184)$ & $\begin{array}{l}507.9 \\
(200.7)\end{array}$ & $500(72,892)$ & $-95.80^{*}$ & $\begin{array}{l}-141.62 \\
-49.99\end{array}$ \\
\hline From proteins & $\begin{array}{l}288.3 \\
(92.9)\end{array}$ & $272(132,652)$ & $\begin{array}{l}255.7 \\
(76.7)\end{array}$ & $248(108,420)$ & $-32.66^{*}$ & $-49.77,-15.55$ \\
\hline From fat & $\begin{array}{l}431.9 \\
(235.1)\end{array}$ & $387(0,1620)$ & $\begin{array}{l}375.9 \\
(124.2)\end{array}$ & $378(0,747)$ & $-56.06^{*}$ & $\begin{array}{l}-101.58,- \\
10.55\end{array}$ \\
\hline
\end{tabular}

$S D$ Standard deviation

${ }^{*} p<0.05$

(mean reduction of -6.57 ; 95\% CI: $-12.73,-0.41, p=$ $0.0184)$. Moreover, we noted a decrease in total caloric intake $(-189.83 \mathrm{Kcal} /$ day; 95\% CI: $-270.6,-109.0, p=$ $0.00001)$, including a reduction in calories from carbohydrates (-95.8 Kcal/day; 95\% CI: $-141.62,-49.99$, p = $0.00001)$, followed by fat $(-56.06 \mathrm{Kcal} /$ day; $95 \% \mathrm{CI}$ : $101.58,-10.55, p=0.0081)$, and protein $(-32.66 \mathrm{Kcal} /$ day; $95 \% \mathrm{CI}:-49.77,-15.55, p=0.0001)$.

Table 4 depicts that the positive effects of CGM remained statistically significant after controlling for patients' baseline characteristics and missing data in the intervention group. The effects include: a decrease in glycemic variability $(-3.94 ; 95 \% \mathrm{CI}:-7.59,-0.29, p=$ $0.034)$, an increase in the percentage of time in range (+ 7.25; $95 \%$ CI: $1.65,12.85, p=0.011$ ); a reduction in the percentage of time above $180 \mathrm{mg} / \mathrm{dl}(-6.01 ; 95 \% \mathrm{CI}$ : -
$12.08,-0.13, p=0.045$ ); and improvements in dietary patterns, shown by a reduction in calories from carbohydrates (-95.68 Kcal; 95\% CI: $-141.95,-49.42, p=0.0001)$, fat $(-62.75 \mathrm{Kcal} ; 95 \% \mathrm{CI}:-112.83,-12.67, p=0.014)$, and protein $(-33.61 \mathrm{Kcal} /$ day; $95 \% \mathrm{CI}:-50.68,-16.54$, $\mathrm{p}=0.0001)$ and a reduction in total caloric intake $(-197.66 \mathrm{Kcal} /$ day; 95\% CI: $-282.87,-112.467, p=0.0001)$.

\section{Discussion}

This study showed significant positive effects of professional CGM as an adjuvant educational tool for improving glycemic control of patients with type 2 diabetes, as reflected in the additional $0.481 \%$ points decrease of HbA1c levels in the intervention group compared with the control group in the three-month follow-up. The 
Table 4 Changes in continuous glucose monitoring data and dietary patterns in intervention group after controlling for patients' baseline characteristics and missing data

\begin{tabular}{|c|c|c|}
\hline & IP-weighted Coefficient & $\begin{array}{l}\text { IP-weighted } \\
95 \% \text { Confidence Intervals }\end{array}$ \\
\hline Mean glucose levels, mg/dl & -10.44 & $-21.83,0.96$ \\
\hline Glycemic variability measured through standard deviation & $-3.94^{*}$ & $-7.59,-0.29$ \\
\hline Percentage of time in range $(70-180 \mathrm{mg} / \mathrm{dl})$ & $7.25^{*}$ & $1.65,12.85$ \\
\hline Percentage of time above range (> $180 \mathrm{mg} / \mathrm{dl}$ ) & $-6.10^{*}$ & $-12.08,-0.13$ \\
\hline Percentage of time above range (> $250 \mathrm{mg} / \mathrm{dl}$ ) & -3.05 & $-8.03,1.93$ \\
\hline Percentage of time below range $(<70 \mathrm{mg} / \mathrm{dl})$ & -0.63 & $-1.39,0.12$ \\
\hline Percentage of time below range $(<54 \mathrm{mg} / \mathrm{dl})$ & -0.93 & $-1.97,0.09$ \\
\hline Percentage of the area over the blood concentration-time curve & -8.01 & $-17.5,1.50$ \\
\hline Percentage of the area under the blood concentration-time curve & -0.15 & $-0.32,0.01$ \\
\hline \multicolumn{3}{|l|}{ Dietary patterns } \\
\hline \multicolumn{3}{|l|}{ Daily caloric intake, Kcal/day } \\
\hline Total & $-197.66^{* * *}$ & $-282.87,-112.467$ \\
\hline From carbohydrates & $-95.68^{* * *}$ & $-141.95,-49.42$ \\
\hline From proteins & $-33.61^{* * *}$ & $-50.68,-16.54$ \\
\hline From fat & $-62.75^{*}$ & $-112.83,-12.67$ \\
\hline
\end{tabular}

Each model was controlled for covariates (sex, age, educational level, nutritional status body mass index, time since diagnosis and type of pharmacological treatment) and the baseline treatment modification

${ }^{*} p<0.05 ;{ }^{* *} p<0.01 ;{ }^{* *} p<0.001$

intervention group reached a significant increase in the time in range measurement and decreases in the time above $180 \mathrm{mg} / \mathrm{dl}$, glucose variability, and total caloric intake.

In our study, physicians and dietitians used CGM information to adjust pharmacological and dietary treatment and to educate patients on self-care based on detailed and patient-friendly glucose pattern summaries and glucose profile curves. Previous studies have shown the potential of professional CGM as an educational tool for improving glycemic control in patients with type 1 and type 2 diabetes [7,9]. Professional CGM generates a simplified report that has standardized statistics, targets, and visual representations of glucose patterns over time, which can educate patients on how insulin, daily activities, and diet impact their blood glucose levels. This information can inform and empower patients in their treatment decision-making, as well as their understanding of treatment plans and patient-centered treatment goals [7-10, 27].

Routine blood glucose measurement methods show disadvantages when compared to CGM. For example, HbA1c measurements and patient self-monitoring of blood glucose do not identify glucose variability. Daily self-monitoring of blood glucose is a static snapshot of glucose levels, and it is painful and challenging to maintain [28]; its use ranges between 2.7 and 4.4 times/day [29]. Meanwhile, professional CGM provides continuous information on glycemic control beyond HbA1c, thus identifying glucose variability and timing related to hyperglycemia and hypoglycemia [7]. Although professional CGM is a retrospective method, the healthcare practice in general is moving towards real-time monitoring that generates data that is accessible to patients, and which can be remotely shared with health professionals and used to develop an artificial pancreas system [30].

Our intervention improved glucose parameters and caloric intake; namely, a significant increase in the time in range and decrease in hyperglycemia, glucose variability, and caloric intake in the intervention group. These results align with similar interventions that have shown a decrease in glucose variability and caloric intake in patients with type 2 diabetes after using CGM to guide their pharmacological and non-pharmacological treatment [7, 9]. For instance, a study from South Korea showed that CGM monitoring in patients with type 2 diabetes for 3 days monthly over 3 months modified patients' glucose profile and reduced their caloric intake by $168.7 \mathrm{kcal} /$ day [31]. Another three-month observational study from the United States showed that a lifestyle intervention combined with CGM reduced total energy intake by $884 \mathrm{Kcal}$ and total carbohydrate intake by $92.8 \mathrm{~g}$ [32].

The mean reduction of HbA1c levels by $0.481 \%$ points 3 months after its application in the intervention group compared with the control group demonstrates additional value of CGM. This result is consistent with previous studies. A recent CGM systematic review that included seven randomized controlled trials and three 
cohort studies involving 1384 patients with type 2 diabetes with RT-CGM and P-CGM and 4902 patients with FGM, showed that CGM was associated with a modest but statistically significant reduction in $\mathrm{HbA} 1 \mathrm{c}$ of $0.20 \%$ (95\% CI -0.31 to -0.09 ) compared with traditional glucose self-monitoring [8]. This finding is noteworthy as $\mathrm{HbA1c}$ is a reliable biomarker for diabetes diagnoses and measures chronic hyperglycemia, which is correlated with long-term diabetes complications [33]; it is also associated with an increased risk for cardiovascular complications and all-cause mortality among patients with type 2 diabetes [34]. The relative risk associated with a $1 \%$ increase in HbA1c level among patients with type 2 diabetes was 1.15 (95\% CI, 1.11 to 1.20 ) for all-cause mortality and 1.17 (95\% CI, 1.12 to 1.23 ) for cardiovascular disease [34]. Furthermore, it is reasonable to assume that the use of CGM and consequent improvements in $\mathrm{HbA1C}$ levels could reduce the use of healthcare services and the corresponding costs of care. This assumption is supported by several studies that have compared healthcare utilization and costs of patients with and without real-time CGM [12, 13, 35].

The study has several limitations. First, it was a pilot study with intervention and control groups and ex-ante and ex-post evaluations in one family medicine clinic. This design is "quasi-experimental" because assignment into the intervention and control groups was not random, which could compromise the interpretation of results if baseline measurements differed between the groups, as they did for baseline treatment and HbA1c levels in our study. We addressed these dissimilarities by using the Diff-in-Diff estimator analysis. Second, we did not document study participants' adherence to pharmacological and non-pharmacological recommendations (e.g., regular physical exercise). Third, the dietary and glucose patterns were only measured in the intervention group due to logistical restrictions. Fourth, the dietary patterns were assessed through self-reporting, which risks over- or under-estimating the effect of the intervention. Nonetheless, most studies on primary care services have applied this type of questionnaire because of its feasibility.

\section{Conclusion}

Primary care services deliver a majority of care for patients with type 2 diabetes. Care for these patients is complex and requires interprofessional collaboration. Our results indicate that in the context of Latin American countries, the professional CGM may be a useful tool for accurate data that can guide the therapeutic and educational decisions of health providers treating patients with type 2 diabetes. Further studies to ascertain the feasibility, costeffectiveness, and other potential benefits of expanding the use of this technology in healthcare settings could further inform decision-making.

\section{Abbreviations}

BMl: Body mass index; CGM: Continuous glucose monitoring; $95 \% \mathrm{Cl}$ : 95\% confidence interval; CGr: Control group; Diff-in-Diff: Differences-in-differences; FGM: Intermittently viewed/flash glucose monitoring; HbA1c: Hemoglobin A1c; IGr: Intervention groups; IP-weighting: Inverse probability weighting; ISSSTE: Institute of Social Security and Services for State Workers (Instituto de Seguridad y Servicios Sociales de los Trabajadores del Estado); LMICs: Lowand middle-income countries; MIDE: Comprehensive Diabetes Care program (MIDE by its Spanish acronym); RT-CGM: Real-time monitoring (stand-alone or connected to a pump); SMBG: Self-monitoring of blood glucose; SD: Standard deviation

\section{Acknowledgements}

None.

\section{Authors' contributions}

D.A.R.A., A.I.E.L., C.R.S.L., and K.J. conceptualized the study; D.A.R.A., A.I.E.L., and C.R.S.L. prepared, and registered the study protocol at ISSSTE EthicS Committee and participated in the supervision of the fieldwork; D.A.R.A. and S.V.D. conducted the literature review and performed statistical analysis; S.V.D. participated in the writing of the first draft of the manuscript; D.A.R.A. and K.J. critically reviewed the manuscript for significant intellectual content. All authors read and approved the final version of the manuscript, have participated sufficiently in the work to take public responsibility for appropriate portions of the content and agreed to be accountable for all aspects of the work in ensuring that questions related to the accuracy or integrity of any part of the work are appropriately investigated and resolved.

\section{Funding}

This study received financial support from Medtronic PLC. Award/Grant number is not applicable.

\section{Availability of data and materials}

The raw database generated and analysed during the current study are not publicly available, as this was not part of the participant consent process; however, the database is available from the corresponding author on reasonable request.

\section{Declarations}

\section{Ethics approval and consent to participate}

The study was approved by the ISSSTE Ethics Committee (registry number 318.17). Prior to participation, participants received information about the aims of the study and study activities (e.g., procedures, number of visits, etc). All included participants agreed to participate and signed an informed consent form.

All study methods were carried out in accordance with relevant guidelines and regulations.

\section{Consent for publication}

Not applicable.

\section{Competing interests}

$\mathrm{KJ}$ is an employee of Medtronic PLC. The authors declare their complete independence from Medtronic PLC during the entire research process and are solely responsible for the methods, results, concepts, and conclusions contained in this manuscript.

\section{Author details}

${ }^{1}$ Clínica de Medicina Familiar Oriente, Instituto de Seguridad y Servicios Sociales de los Trabajadores del Estado, Ciudad de México, Mexico.

${ }^{2}$ Enseñanza e Investigación, Delegación Oriente, Instituto de Seguridad y Servicios Sociales de los Trabajadores del Estado, Ciudad de México, Mexico. ${ }^{3}$ Delegación Oriente, Instituto de Seguridad y Servicios Sociales de los Trabajadores del Estado, Ciudad de México, Mexico. ${ }^{4}$ Medtronic, Ciudad de México, Mexico. ${ }^{5}$ Epidemiology and Health Services Research Unit, CMN Siglo XXI, Mexican Institute of Social Security, Av. Cuauhtemoc 330, Col. Doctores, Del. Cuauhtemoc, 06720 Mexico City, Mexico. 
Received: 28 January 2021 Accepted: 19 March 2021

\section{Published online: 23 April 2021}

\section{References}

1. International Diabetes Federation. IDF diabetes atlas. 9th ed: International Diabetes Federation; 2019. Available at: www.diabetesatlas.org

2. Rodriguez-Gutierrez R, Gonzalez-Gonzalez JG, Zuñiga-Hernandez JA, McCoy RG. Benefits and harms of intensive glycemic control in patients with type 2 diabetes. BMJ. 2019;367:15887. https://doi.org/10.1136/bmj.l5887.

3. Ratner RE. Glycemic control in the prevention of diabetic complications. Clin Cornerstone. 2001;4(2):24-37. https://doi.org/10.1016/s1098-3597(01 )90027-4.

4. Manne-Goehler J, Geldsetzer P, Agoudavi K, Andall-Brereton G, Aryal KK, Bicaba BW, et al. Health system performance for people with diabetes in 28 low- and middle-income countries: a cross-sectional study of nationally representative surveys. PLoS Med. 2019;16(3):e1002751. https://doi.org/10.13 71/journal.pmed.1002751.

5. Krhač M, Lovrenčić MV. Update on biomarkers of glycemic control. World J Diabetes. 2019;10(1):1-15. https://doi.org/10.4239/wjd.v10.i1.1.

6. Kumar R, Raviteja KV, Sachdeva N, Dayal D. Feasibility and acceptability of professional continuous glucose monitoring system in children with type 1 diabetes mellitus: an observational study. J Diabetol. 2019;10(1):15-20. https://doi.org/10.4103/jod.jod_13_18.

7. Carlson AL, Mullen DM, Bergenstal RM. Clinical use of continuous glucose monitoring in adults with type 2 diabetes. Diabetes Technol Ther. 2017; 19(S2):S4-S11. https://doi.org/10.1089/dia.2017.0024.

8. Park C, Le QA. The effectiveness of continuous glucose monitoring in patients with type 2 diabetes: a systematic review of literature and metaanalysis. Diabetes Technol Ther. 2018;20(9):613-21. https://doi.org/10.1089/ dia.2018.0177.

9. Taylor PJ, Thompson CH, Brinkworth GD. Effectiveness and acceptability of continuous glucose monitoring for type 2 diabetes management: a narrative review. J Diabetes Investig. 2018;9(4):713-25. https://doi.org/1 $0.1111 /$ jdi.12807.

10. Murphy HR, Rayman G, Lewis K, Kelly S, Johal B, Duffield K, et al. Effectiveness of continuous glucose monitoring in pregnant women with diabetes: randomised clinical trial. BMJ. 2008;337(sep25 2):a1680. https://doi. org/10.1136/bmj.a1680.

11. Teodoro de Oliveira AO, Bartholomew K, Lavin-Tompkins J, Sperl-Hillen J. Use of continuous glucose monitoring as an educational tool in the primary care setting. Diabetes Spectr. 2013;26(2):120-3. https://doi.org/10.2337/dia spect.26.2.120.

12. Gill M, Zhu C, Shah M, Chhabra H. Health care costs, hospital admissions, and glycemic control using a standalone, real-time, continuous glucose monitoring system in commercially insured patients with type 1 diabetes. J Diabetes Sci Technol. 2018;12(4):800-7. https://doi.org/10.1177/193229681 8777265.

13. Parkin CG, Graham C, Smolskis J. Continuous glucose monitoring use in type 1 diabetes: longitudinal analysis demonstrates meaningful improvements in $\mathrm{HbA1c}$ and reductions in health care utilization. J Diabetes Sci Technol. 2017;11(3):522-8. https://doi.org/10.1177/1932296817693253.

14. Bruttomesso D, Laviola L, Avogaro A, Bonora E, del Prato S, Frontoni S, et al. The use of real time continuous glucose monitoring or flash glucose monitoring in the management of diabetes: a consensus view of Italian diabetes experts using the Delphi method. Nutr Metab Cardiovasc Dis. 2019;29(5):421-31. https://doi.org/10.1016/j.numecd.2019.01.018.

15. Reddy N, Verma N, Dungan K. Monitoring technologies- continuous glucose monitoring, mobile technology, biomarkers of glycemic control. In: Feingold KR, Anawalt B, Boyce A, et al., editors. Endotext. South Dartmouth: MDText. com, Inc.; 2000. [Updated 2020 Aug 16]. Available from: https://www.ncbi. nlm.nih.gov/books/NBK279046/.

16. Basto-Abreu A, Barrientos-Gutiérrez T, Rojas-Martínez R, Aguilar-Salinas CA, López-Olmedo N, de la Cruz-Góngora V, et al. Prevalence of diabetes and poor glycemic control in Mexico: results from Ensanut 2016. Salud Publica Mex. 2020;62(1):50-9. https://doi.org/10.21149/10752.

17. ISSSTE. Estadística. Anuarios 2019. Capítulo 1. Estadísticas de población. Población Amparada por Entidad Federativa. Mexico; 2019. Availabale at: http://www.issste.gob.mx/datosabiertos/anuarios/anuarios2019.html\#cap1. Accessed 7 Aug 2020.

18. Instituto de Seguridad y Servicios Sociales de los Trabajadores del Estado. Mexico. Prensa 14 de Noviembre de 2019. https://www.gob.mx/issste/ prensa/la-diabetes-es-la-segunda-causa-de-muerte-en-el-issste-ramirezpineda?idiom=es; https://www.gob.mx/issste/prensa/llama-el-issste-a-reforza r-la-prevencion-de-diabetes-y-obesidad-por-su-alta-incidencia-entre-la-pobla cion. Accessed 22 Feb 2020

19. Blanco-Cornejo M, Riva-Palacio-Chiang-Sam IL, Sánchez-Díaz I, et al. New model for diabetes primary health care based on patient empowerment and the right to preventive health: the MIDE program. Rev Panam Salud Publica. 2017;41:e128. https://doi.org/10.26633/RPSP.2017.128.

20. Danne T, Nimri R, Battelino T, Bergenstal RM, Close KL, DeVries JH, et al. International consensus on use of continuous glucose monitoring. Diabetes Care. 2017;40(12):1631-40. https://doi.org/10.2337/dc17-1600.

21. Rosner B. Fundamentals of biostatistics. 5th ed. Pacific Grove: Duxbury Ress; 2000

22. Villa JM. Diff: simplifying the estimation of difference-in-differences treatment effects. Stata J. 2016;16(1):52-71. https://doi.org/10.1177/153 6867X1601600108.

23. Dziura JD, Post LA, Zhao Q, Fu Z, Peduzzi P. Strategies for dealing with missing data in clinical trials: from design to analysis. Yale J Biol Med. 2013; 86(3):343-58.

24. Hernán MA, Robins JM. Causal inference. Boca Raton: Chapman \& Hall/CRC; 2015.

25. Seaman SR, White IR. Review of inverse probability weighting for dealing with missing data. Stat Methods Med Res. 2013;22(3):278-95. https://doi. org/10.1177/0962280210395740.

26. Bergenstal RM. Understanding continuous glucose monitoring data. In: Role of continuous glucose monitoring in diabetes treatment. Arlington: American Diabetes Association; 2018. Available from: https://www.ncbi.nlm. nih.gov/books/NBK538967/. https://doi.org/10.2337/db20181-20.

27. Lawton J, Blackburn M, Allen J, Campbell F, Elleri D, Leelarathna L, et al. Patients' and caregivers' experiences of using continuous glucose monitoring to support diabetes self-management: qualitative study. BMC Endocr Disord. 2018;18(1):12. https://doi.org/10.1186/s12902-018-0239-1.

28. Aleppo G. Approaches for successful outcomes with continuous glucose monitoring. In: Role of continuous glucose monitoring in diabetes treatment. Arlington: American Diabetes Association; 2018. Available from: https://www.ncbi.nlm.nih.gov/books/NBK538974/. https://doi.org/10.2337/ db20181-13.

29. Glooko. Annual diabetes report 2017. Available from www.glooko.com/ resource/2017-annual-diabetes-report. Accessed 3 Mar 2018.

30. Rodbard D. Continuous glucose monitoring: a review of recent studies demonstrating improved glycemic outcomes. Diabetes Technol Ther. 2017; 19(S3):S25-37. https://doi.org/10.1089/dia.2017.0035.

31. Yoo HJ, An HG, Park SY, Ryu OH, Kim HY, Seo JA, et al. Use of a real time continuous glucose monitoring system as a motivational device for poorly controlled type 2 diabetes. Diabetes Res Clin Pract. 2008;82(1):73-9. https:// doi.org/10.1016/j.diabres.2008.06.015.

32. Cox DJ, Taylor AG, Moncrief M, Diamond A, Yancy WS Jr, Hegde S, et al. Continuous glucose monitoring in the self-management of type 2 diabetes: a paradigm shift. Diabetes Care. 2016;39(5):E71-3. https://doi.org/10.2337/ dc15-2836.

33. Sherwani SI, Khan HA, Ekhzaimy A, Masood A, Sakharkar MK. Significance of $\mathrm{HbA1c}$ test in diagnosis and prognosis of diabetic patients. Biomark Insights. 2016;11:95-104. https://doi.org/10.4137/BMI.S38440.

34. Zhang Y, Hu G, Yuan Z, Chen L. Glycosylated hemoglobin in relationship to cardiovascular outcomes and death in patients with type 2 diabetes: a systematic review and meta-analysis. PLoS One. 2012;7(8):e42551. https:// doi.org/10.1371/journal.pone.0042551.

35. Sierra JA, Shah M, Gill MS, Flores Z, Chawla H, Kaufman FR, et al. Clinical and economic benefits of professional CGM among people with type 2 diabetes in the United States: analysis of claims and lab data. J Med Econ. 2018;21(3): 225-30. https://doi.org/10.1080/13696998.2017.1390474.

\section{Publisher's Note}

Springer Nature remains neutral with regard to jurisdictional claims in published maps and institutional affiliations. 